\title{
Effect of Fatty Acid Saturation on the Distribution of the Cholesterol Moiety of Very Low Density Lipoproteins *
}

\author{
Norton SPRITZ $\dagger$ \\ (From the Lipid Metabolism Laboratory of the Second [Cornell] Medical Division, Bellevue \\ Hospital, and the Department of Medicine, Cornell University, Medical College, \\ New York, N. Y.)
}

The nonesterified cholesterol of each plasma lipoprotein fraction is in rapid exchange with that of red cells, liver, and other circulating lipoproteins (1-5). Although this dynamic equilibrium has been demonstrated in many species, including man, the factors determining the dynamics of this exchange and the resultant distribution of labeled cholesterol have not been elucidated. The present experiments, designed to test the possibility that the degree of saturation of the esterified fatty acids of lipoproteins could be such a factor, indicate that isotopic cholesterol associated with very low density lipoproteins composed largely of unsaturated fatty acids appears in other cholesterol pools more rapidly than that of saturated lipoproteins during both in vivo and in vitro equilibrations.

\section{Methods}

Female New Zealand white rabbits weighing 1,800 to $2,500 \mathrm{~g}$ were utilized. Diets consisted of standard rabbit Purina chow to which $10 \%$ safflower or coconut oils ${ }^{1}$ and $1 \%$ cholesterol ${ }^{2}$ had been added. 4- $\mathrm{C}^{14}$ - and $7 \alpha-\mathrm{H}^{3}$ cholesterol ${ }^{3}$ were purified by preparative thin layer chromatography before use. Thin layer chromatoplates were prepared with binder-free silicic acid 4 and were 0.5 $\mathrm{mm}$ in thickness (6).

\section{In vivo studies}

Summary of general experimental design (Figure 1). Three lipemic rabbits that had received diets containing coconut oil and three that had received safflower oil were given $0.1 \mathrm{mc}$ of tritiated or $.03 \mathrm{mc}$ of $\mathrm{C}^{\mathbf{1 4}}$-cholesterol in-

* Submitted for publication June 15, 1964; accepted November 5, 1964.

Supported by U. S. Public Health Service grant NB03346-03.

† Established Investigator of the Health Research Council of New York (I-128).

1 E. F. Drew Co., Boonton, N. J.

2 Nutritional Biochemicals Corp., Cleveland, Ohio.

3 New England Nuclear Corp., Boston, Mass.

4 Silica gel H, Merck \& Co., Rahway, N. J. traperitoneally in a small volume of $50 \%$ ethanol. The animals were exsanguinated 12 to 14 hours later and the very low density lipoproteins $(<1.019$ fraction $)$ harvested from their sera. This fraction from a safflowerfed animal was combined with one from an animal fed coconut oil and the mixture injected intravenously into a recipient rabbit. The fractions were selected so that in each study the cholesterol of one donor was labeled with $\mathrm{C}^{16}$ and the other with tritium. The recipients were sacrificed 30 to 210 minutes after injection, and the ratio of the two isotopes was determined in the free and esterified fractions of their red cells, liver, whole serum, and $<1.019$ and $>1.019$ lipoprotein fractions. These isotope ratios were then compared to that injected. Changes in ratios were considered to indicate differences in dynamics of the cholesterol moiety of each type of lipoprotein. Each of these steps is discussed in more detail in the following paragraphs.

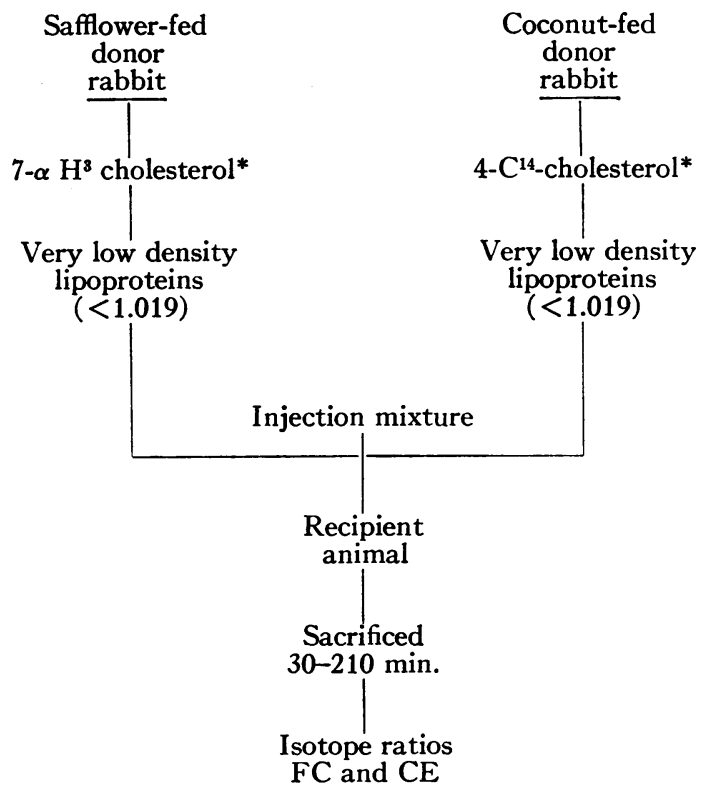

Fig. 1. OUTLINE OF THE EXPERIMENTAL DESIGN. FC = nonesterified cholesterol; $\mathrm{CE}=$ cholesterol ester.

* In experiments 2 and $3 \mathrm{H}^{3}$ and $\mathrm{C}^{14}$ isotopes were reversed. 


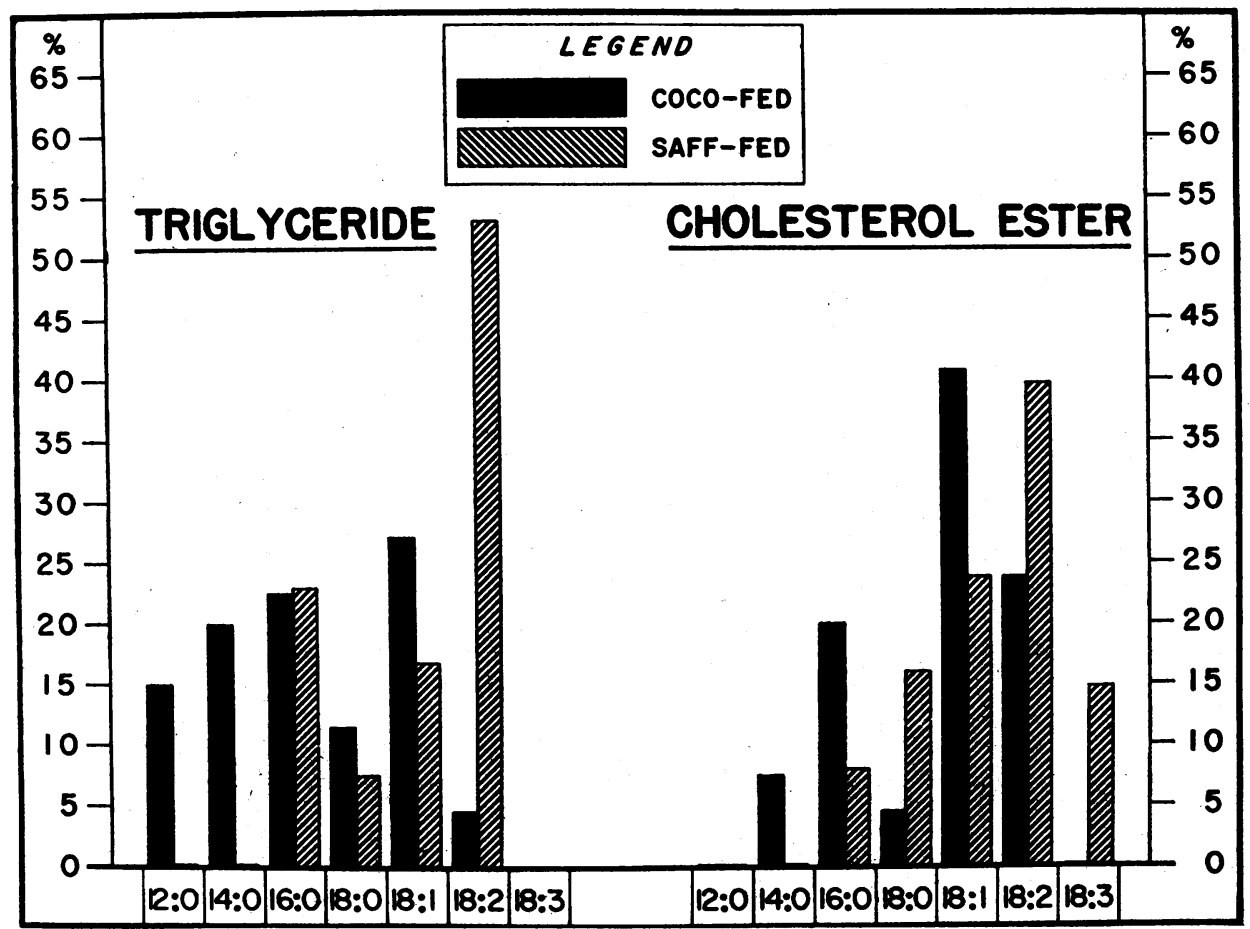

Fig. 2. FATTY ACID COMPOSITION OF TRIGLYCERIDE AND CHOLESTEROL ESTER FRACTION OF INJECTED $<1.019$ FRACTION. The predominance of polyunsaturated fatty acids in both lipid classes obtained from the $<1.019$ fraction of the safflower-oil-fed rabbits is illustrated. This effect is more marked in the triglyceride than cholesterol ester fraction. Very similar patterns were obtained in material from all donor animals. Phospholipid fatty acid composition similarly was affected by dietary fat but less markedly so. The symbols for the fatty acids refer to the number of carbon atoms and the number of double bonds (11).

Preparation of donor lipoproteins. Sera obtained from three lipemic donor animals that had received safflower and three that had received coconut oil were adjusted to density of 1.019 with $\mathrm{KBr}$ and centrifuged at $105,000 \mathrm{~g}$ for 16 to 20 hours at $5^{\circ} \mathrm{C}(7)$. The contents of the top $1 \mathrm{~cm}$ of the tube were recovered and dialyzed for 48 hours at $5^{\circ} \mathrm{C}$ with nitrogen bubbling used for agitation. The dialysis fluid was a solution of $0.01 \mathrm{M}$ phosphate buffer at $\mathrm{pH} 7.4,0.01 \% N$-ethyl maleimide (NEM), and $0.01 \mathrm{M} \mathrm{Na}$ ethylenediamine tetraacetate (EDTA) in $0.15 \mathrm{~N} \mathrm{NaCl}$. NEM was used to prevent in vitro transesterification of free cholesterol as described by Glomset

TABLE I

Characteristics of the two components of the injection mixtures in each experiment*

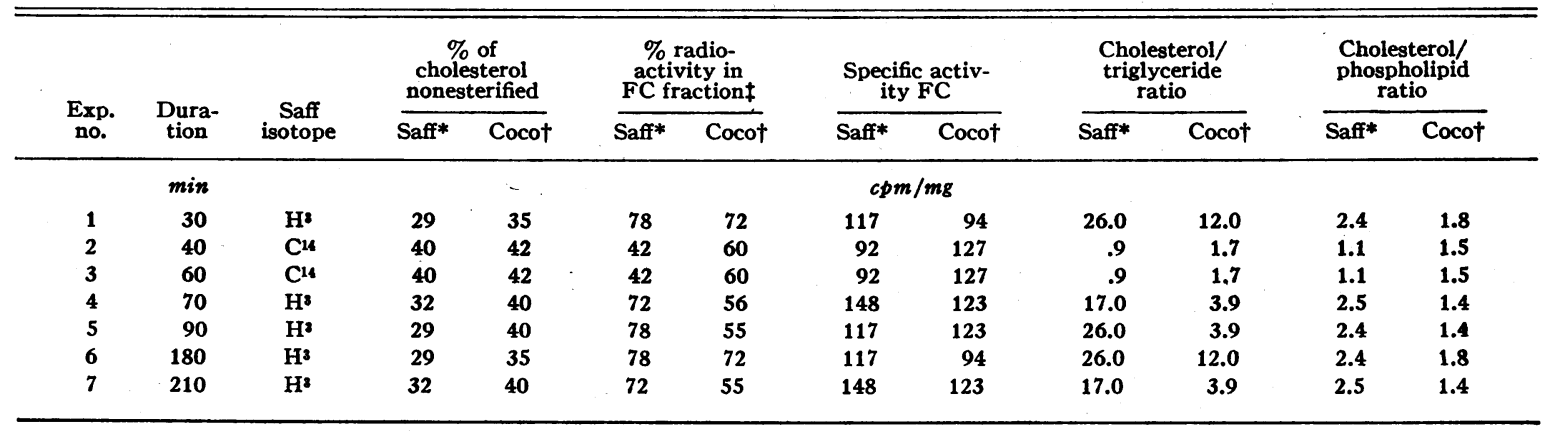

* <1.019 lipoprotein fraction of safflower-oil-fed donor rabbit.

$\dagger<1.019$ lipoprotein fraction of coconut-oil-fed donor rabbit.

$\mathrm{FC}=$ nonesterified cholesterol. 
(8) and EDTA to bind heavy metal oxidation catalysts (9). Figure 2 illustrates the marked difference in fatty acid composition of the cholesterol ester (CE) and triglyceride classes of a representative safflower- and coconut-oil-fed donor group. These data were obtained by an F \& $\mathrm{M}$ model $\mathbf{4 0 0}$ gas liquid chromatograph standardized with N.I.H. solutions D and E (10).

Before mixing, the lipid of each donor lipoprotein solution was extracted and the $\mathrm{CE}$, nonesterified cholesterol (FC), glyceride, and phospholipid fractions were isolated and quantitated by preparative thin layer chromatography $(12,13)$. Table I depicts data obtained from both components of each injection mixture in the seven experiments. Distribution of isotope between esterified and nonesterified cholesterol; the specific activity of the isotopic cholesterol; and cholesterol: phospholipid, cholesterol : triglyceride ratios varied widely among the donors. The values for each of these variables were higher in the lipoproteins from the safflower-fed donors in some experiments and from the coconut-oil-fed donors in others.

Administration of $<1.019$ lipoprotein fraction to recipient animal. The recipient animals, which had been maintained on fat-free diets for at least 4 days before the experiment, were lightly anesthetized with intravenous pentobarbital injection. The $<1.019$ lipoprotein fractions from the two donors were mixed immediately before administration and were injected into an ear vein over a 2 - to 3-minute period. The total volume injected varied from 15 to $30 \mathrm{ml}$ and contained from 20 to $50 \mathrm{mg}$ of lipid. Total radioactivity injected varied from approximately 7,000 to $10,000 \mathrm{cpm}$ of each isotope.

Method of determining isotope ratios in tissues. The recipient animals were killed by exsanguination from the inferior vena cava 30 to 210 minutes after injection. Fifty $\mathrm{ml}$ of blood was clotted and the serum obtained. In three experiments $10 \mathrm{ml}$ of serum was adjusted to density of 1.019 and $a<1.019$ and $>1.019$ lipoprotein fraction obtained as described for the donor sera. Red cells were obtained from approximately $20 \mathrm{ml}$ of blood drawn in a heparinized syringe. These were washed three times in $0.15 \mathrm{M} \mathrm{NaCl}$. The liver was freed from the gallbladder and was cut into numerous small pieces and repeatedly washed with $0.15 \mathrm{M} \mathrm{NaCl}$ until the washings were clear. It was then homogenized in a Waring blendor. Each of these materials was extracted into chloroform: methanol, 2:1, and the FC and $\mathrm{CE}$ fractions were obtained by preparative thin layer chromatography. In one experiment, bile, aorta, kidney, and heart were also obtained, but these contained insufficient radioactivity for accurate counting and were not extracted in subsequent experiments.

Determination of isotope ratios. A Packard dual channel Tri-Carb scintillation counter was used. Scintillator solution was $5 \%$ 2,5-diphenyloxazole and $0.8 \%$ 1,4-bis-2(4-methyl-5-phenyloxazolyl)benzene in toluene. In all instances the activity of both isotopes was at least three times that of its background, and counting was continued at least long enough for the lower counting isotope to be

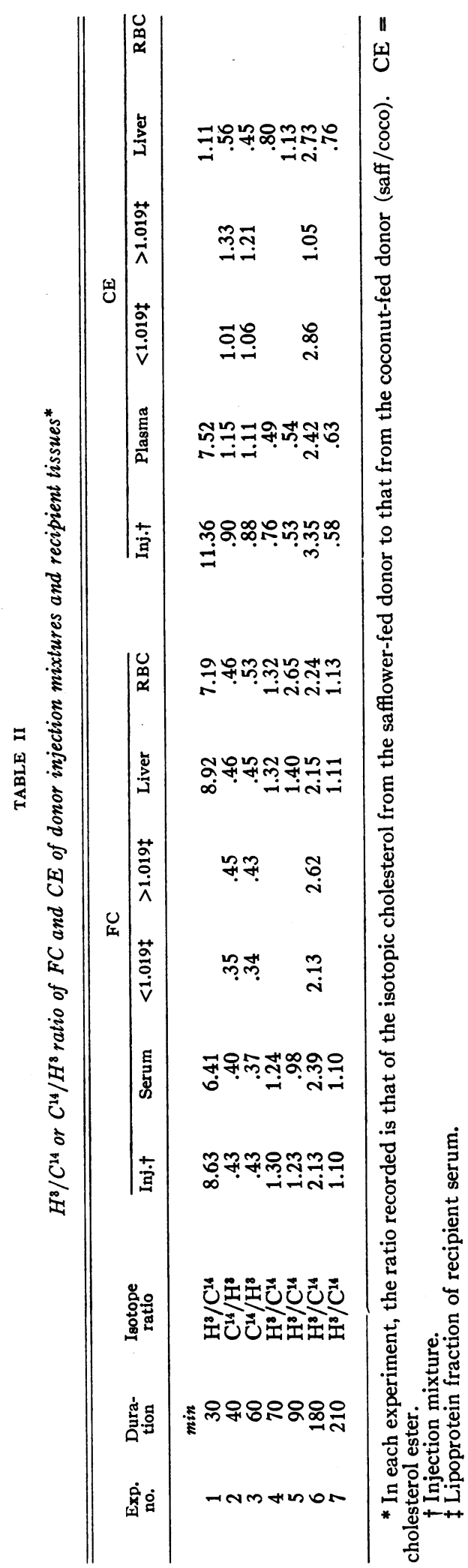



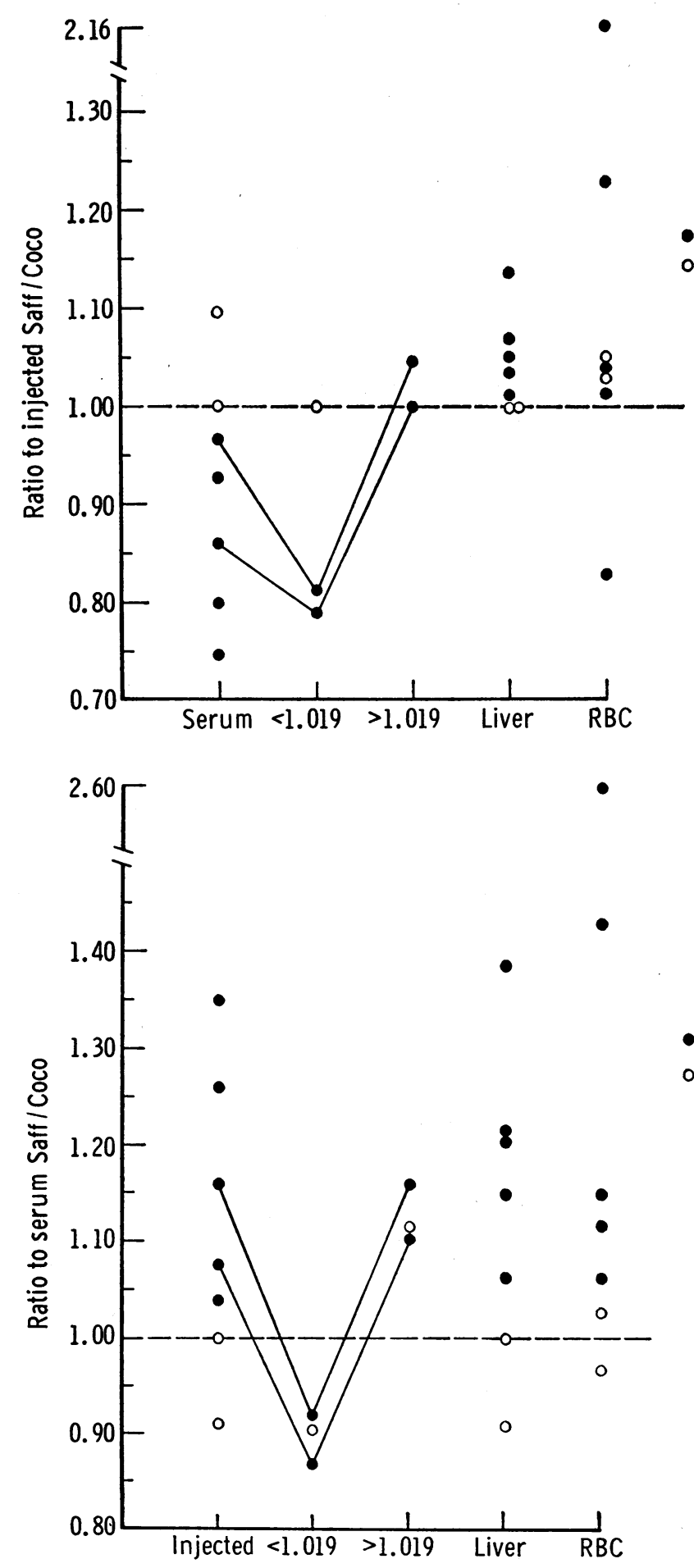

- 30-90 min

$0180-210 \mathrm{~min}$

30-90 min

- 180-210 min

Fig. 3. A) Comparison of SAfp/coco of recipient tissues to that iNJECTED. The saff/coco of the injection mixtures has been adjusted to 1.00 , and comparative values for this ratio in recipient serum, $<1.019$ and $>1.019$ lipoprotein fractions, red cells, and liver FC (nonesterified cholesterol) are depicted. B) CoMparison of INJECTION MIXTURE AND RECIPIENT TISSUES to 
counted with an accuracy of $1 \%$. Isotope ratios, even in those specimens with the least activity, were reproducible with an error of $2 \%$ when separate portions of the tissue to be studied were processed in duplicate.

After sample counting was completed, an $\mathrm{H}^{3}$ and a $\mathrm{C}^{14}$ internal standard was counted in every specimen. This was done to detect quenching for each isotope as well as to determine the ratio of $\mathrm{C}^{14}$ counts between the two channels so that correction of total counts in the $\mathrm{H}^{3}$ channel for $\mathrm{C}^{\mathbf{1 4}}$ could be individualized for each specimen.

\section{In vitro studies}

The sera of two rabbits that had received coconut-oil feedings and two that had received safflower oil were obtained as described above, except that isotopic cholesterol was not administered to the animals. The sera from the safflower-fed animal were incubated with $4-C^{14}$ cholesterol, and those from the coconut-fed animals with $7 \alpha-\mathrm{H}^{3}$ cholesterol as described by Porte and Havel (14). The $<1.019$ fraction was isolated as described above and passed through an $8.0-\mu$ Swinney filter.

A $\mathrm{C}^{14}$ - and $\mathrm{H}^{3}$-labeled lipoprotein fraction was mixed and added to a solution of unlabeled washed human red cells. A sample of the lipoprotein fraction was removed at the beginning of the incubation. At 1-, 2-, and 4- or 1-, $2-$, and 3-hour intervals, a sample of the incubation mixture was removed, and the lipoprotein and red cells were separated as described above. The $\mathrm{C}^{\mathbf{1}} / \mathrm{H}^{\mathbf{3}}$ ratio was then determined separately for the lipoproteins and red cells at intervals up to 4 hours.

\section{Results}

\section{In vivo studies}

Isotope ratios of free cholesterol. $\mathrm{H}^{3} / \mathrm{C}^{14}$ or $\mathrm{C}^{14} / \mathrm{H}^{3}$ ratio was determined for the donor injection mixture and for the tissues obtained from the recipient animals at the end of each experiment. Table II lists the ratio of the isotopic cholesterol from the safflower-fed donor to that from the coconut-fed. This ratio is designated as "saff/ coco." In experiments $1,4,5,6$, and 7 it was $\mathrm{H}^{3} / \mathrm{C}^{14}$, and in the other two it was $\mathrm{C}^{14} / \mathrm{H}^{3}$. Figure $3 \mathrm{~A}$ indicates the ratio of the recipient tissues' saff/coco to that injected, and Figure 3B illustrates the relationship between the whole serum saff/ coco to that injected and the recipient tissues.

In each of the experiments lasting from 30 to 90 minutes, the loss from the serum of the saff-fed donor's isotopic FC was more rapid than that of the coco-fed. This selective loss was indicated by lower saff/coco ratios in the sera of recipients than in the injected mixtures in all five experiments (Figure 3A). This finding was most marked in experiment 1 in which the serum ratio was $74 \%$ of that injected. In experiments 2 and 3, the observed fall in serum FC saff/coco reflected that of its very low density $(<1.019)$ lipoprotein fractions. Although the whole serum ratio had fallen only to 86 and $93 \%$ of the injected, that of the $<1.019$ lipoprotein fraction in these two studies was 82 and $81 \%$, respectively. Conversely, liver FC saff/coco exceeded that injected, indicating selective accumulation of the isotopic cholesterol from the safflower donor lipoprotein in that organ. Red blood cell FC saff/coco exceeded that injected in four of the five experiments lasting 30 to 90 minutes.

Figure $3 \mathrm{~B}$ more strikingly illustrates this selective distribution of isotopic FC in the 30- to 90minute experiment. In every instance the $>1.019$ lipoprotein, liver, and red cell FC saff/coco exceeded that of whole serum obtained simultaneously. The saff/coco of the $<1.019$ fraction, the material injected, was even lower than that of the whole serum, further indicating selective loss of isotopic cholesterol from the donor lipoprotein and its selective accumulation in recipient tissues.

In experiment 6 , lasting 180 minutes, the FC saff/coco of the $<1.019$ fraction in the recipient rabbit equaled that injected, whereas the higher density lipoproteins $(>1.019)$ continued to show selective accumulation of the isotopic cholesterol from the saff-fed donor. In the 210-minute experiment (no. 7) selective distribution was no longer evident; whole serum, liver red cell, and injected FC saff/coco now being equal.

Esterified cholesterol ratios. It is evident from Table II that considerable change from the injected saff/coco ratio occurred in the plasma and liver $\mathrm{CE}$. Unlike the FC, however, no consistent pattern for this change in plasma could be established; the ratio in plasma exceeded the ratio in

SERUM SAFF/coco. The saff/coco of the recipient serum obtained at the end of each experiment has been adjusted to 1.00 , and comparative values for this ratio in the donor mixture and the recipient $<1.019$ and $>1.019$ lipoproteins, red cells, and liver FC are depicted. "Saff/coco" refers to the ratio of the isotopic cholesterol from the safflower-fed donor to that from the coconut-fed. 


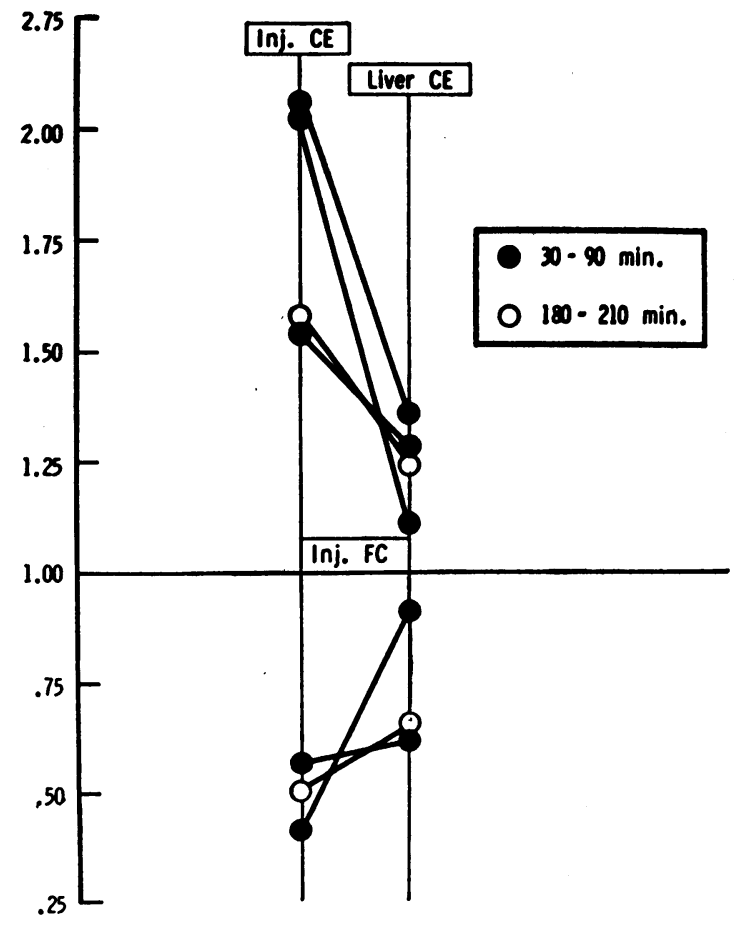

Fig. 4. Comparison of injected and Liver CE SAFF/ COCO TO INJECTED FC SAFF/coco. The saff/coco of the injected FC has been adjusted to 1.00 in all instances. Comparison of the injected CE (cholesterol ester) to injected FC saff/coco appears on the left vertical line and comparison between liver $\mathrm{CE}$ saff/coco and injected FC on the right. The diagonal lines connect values obtained in a single experiment. In all instances, the liver $\mathrm{CE}$ saff/coco reached a value intermediate between the injected $\mathrm{CE}$ and FC.

the injected lipoprotein in three experiments, was equal in one, and less in the other three.

Similarly liver CE saff/coco varied widely from that injected and that of plasma obtained at the end of the experimental period. A constant interrelationship among the saff/coco of the injected $\mathrm{CE}$, liver $\mathrm{CE}$, and the injected $\mathrm{FC}$ was noted, however, and is illustrated in Figure 4 . In all instances, the liver $\mathrm{CE}$ saff/coco was intermediate between the ratio for injected $\mathrm{CE}$ and FC. This relationship was noted whether the injected $\mathrm{FC}$ saff/coco was greater or less than that of the CE and suggests that hepatic $\mathrm{CE}$ in these studies received contributions both directly from circulating $\mathrm{CE}$ and from esterification of circulating $\mathrm{FC}$.

Per cent of total radioactivity in $F C$ and $C E$ fractions. Table III depicts mean values and ranges for the per cent of isotope in the $\mathrm{CE}$ frac-
TABLE III

Mean and range of per cent of isotope in cholesterol ester fraction of injected material, serum, and liver

\begin{tabular}{|c|c|c|c|}
\hline & Saff isotope & Coco isotope & $\begin{array}{r}\text { Total } \\
\text { isotope }\end{array}$ \\
\hline $\begin{array}{l}\text { Injected } \\
\text { lipoprotein } \\
\text { mixture }\end{array}$ & $\begin{array}{c}34 \\
(22 \text { to } 58)\end{array}$ & $\begin{array}{c}38 \\
(28 \text { to } 45)\end{array}$ & 36 \\
\hline $\begin{array}{l}\text { Recipient } \\
\text { serum }\end{array}$ & $\begin{array}{l}65 \\
\text { (32 to } 84)\end{array}$ & $\begin{array}{c}64 \\
(54 \text { to } 84)\end{array}$ & 65 \\
\hline $\begin{array}{l}\text { Recipient } \\
\text { liver }\end{array}$ & ( 3 to 21 ) & $\begin{array}{c}17 \\
(4 \text { to } 30)\end{array}$ & 16 \\
\hline
\end{tabular}

tion of the injection mixture, serum, and liver for each isotope and the total. The per cent esterified was higher in serum than that injected in all experiments, and in the liver the per cent esterified was considerably below both that injected and the serum.

\section{In vitro experiments}

Table IV compares the $\mathrm{C}^{14} / \mathrm{H}^{3}$ ratios in the $<1.019$ fraction and red cells after 1 to 4 hours of incubation at $37^{\circ} \mathrm{C}$. In both experiments the isotopic cholesterol from the safflower-fed animal's lipoproteins $\left(\mathrm{C}^{14}\right)$ was higher in the red cells and reciprocally lower in the lipoproteins than in the original mixture (adjusted to 1.00).

TABLE IV

Incubation of mixture of in vitro-labeled lipoproteins with unlabeled red cells

\begin{tabular}{|c|c|c|c|c|c|c|c|c|}
\hline \multirow[b]{3}{*}{$\begin{array}{c}\text { Exp. } \\
\text { no. }\end{array}$} & \multicolumn{8}{|c|}{$\mathrm{C}^{14} / \mathrm{H}^{2}$ ratio } \\
\hline & \multirow{2}{*}{$\begin{array}{l}\text { Mixture } \\
\text { of saff } \\
\text { and coco }\end{array}$} & \multicolumn{3}{|c|}{ RBC } & \multicolumn{4}{|c|}{ Lipoprotein mixture } \\
\hline & & 1 & \begin{tabular}{ll}
\multicolumn{2}{c}{ Hours } \\
2
\end{tabular} & 4 & 1 & ${ }_{2}^{H}$ & $\begin{array}{r}\text { ours } \\
3\end{array}$ & 4 \\
\hline 1 & 1.00 & 12.3 & 3.8 & 3.4 & 0.51 & 0.77 & & 0.64 \\
\hline 2 & 1.00 & 4.1 & $4.5 \quad 2.0$ & & 0.84 & 0.83 & 0.89 & \\
\hline
\end{tabular}

\section{Discussion}

The experiments described in this study were designed to permit the determination of the effect of fatty acid composition on the distribution of lipoprotein cholesterol. The use of double isotope technique made it possible to compare the fate of injected isotopic cholesterol associated with highly unsaturated to saturated lipoproteins within a single animal. These experiments indicate that isotopic free cholesterol associated with unsatu- 
rated very low density lipoproteins leaves these lipoproteins and appears in red cells, liver, and lower density lipoproteins more rapidly than that of the saturated lipoproteins.

These findings could result from any or a combination of the following events: 1) Exchange of isotopic cholesterol between the injected lipoproteins and the recipient tissue was without change in the cholesterol content of either. In this case, both the transfer of cholesterol from the injected lipoproteins as well as its replacement by nonlabeled recipient cholesterol would have proceeded more rapidly for the safflower lipoproteins than for the lipoproteins from coconut-fed animals. 2) Net transfer of FC from the injected unsaturated lipoproteins to recipient tissues was more rapid than from the saturated lipoproteins. 3) Distribution of intact injected lipoproteins with their component isotopic FC molecules at selective rates was influenced by fatty acid composition.

The relative role of each of these mechanisms cannot be determined from this study. Exchange of FC molecules is the most likely explanation for the appearance of radioactivity in the $>1.019$ lipoprotein in vivo and for the red cells in both the in vivo and in vitro studies, although net transfer has not been excluded.

On the other hand, previously reported studies in which the glyceride portion of chylomicra was isotopically labeled (15-17) suggest that the isotope appearing in the liver in the present experiment may represent, to some extent, cholesterol still a component of the lipoprotein with which it was injected. Several findings in the present experiments indicate, however, that isotopic liver FC arose primarily from exchange or net transfer of plasma FC rather than from the transport of intact labeled lipoproteins from plasma to liver. In all instances, the per cent of esterified isotope in the liver was far lower than that injected or that of the serum (Table III). This finding, together with an increase in the per cent of isotope esterified in the serum over that injected, is consistent with transfer of isotopic circulating FC (either as exchange or net transfer) while labeled CE remains a part of the plasma lipoprotein. ${ }^{5}$ Further-

$5 \mathrm{~A}$ decrease in the degree of esterification of isotopic cholesterol in liver compared to that in plasma has also been observed by Brot, Lossow, and Chaikoff (18) in in vitro experiments in rats. They interpreted this to more, Nestel and Scow (16) demonstrated that when the chylomicron glyceride was isotopically labeled, the isotope from those chylomicra that were highly saturated disappeared from plasma and appeared in liver more rapidly than that from chylomicra with relatively unsaturated fatty acids. This finding, in association with those of the present experiments, lends further support to the concept that the FC constituent of lipoproteins exchanges with or is transferred to tissues independently of other lipid components $(2,4)$ and that fatty acid composition may affect the dynamics of this fraction differently from that of the whole lipoprotein or its glyceride.

In the experiments of 180 and 210 minutes in the present study, the selectivity of the distribution of the injected double-labeled FC was largely lost. The most likely explanation for this phenomenon is that cholesterol had been redistributed after its initial exchange. Once the isotopic molecules had left the lipoproteins with which they were injected, subsequent exchanges from the tissue to which they had migrated would no longer be selective, and a return of the ratios between isotope to that injected would be expected. The occurrence of a second exchange of cholesterol molecules in the period of time of these experiments is consistent with the known rapid rates of free cholesterol exchange among lipoproteins $(4,5)$, liver, and red cells (1-3).

The role of a second exchange in these findings is further supported by the findings of Naidoo, Lossow, and Chaikoff (19) that isotopic chylomicron cholesterol injected into rats and removed primarily into liver begins to reappear in plasma 50 minutes after injection. In experiment 6 , the persistence of a saff/coco ratio greater than that injected in the recipient's $>1.019$ lipoprotein fraction when liver, red cells, and $<1.019$ fraction had all returned to the injected ratio also supports the contention of these authors that cholesterol transferred from lower to higher density lipoproteins then has a turnover rate slower than that remaining in the lower density lipoproteins.

indicate hydrolysis of circulating $\mathrm{CE}$ as isotopic cholesterol entered hepatic tissue. This interpretation does not explain the findings of the present in vivo study in view of the similarity of hepatic, serum, and injected FC saff/coco and the marked dissimilarity between these ratios and those of the CE fractions (Table II). 
Although the saff/coco ratio of the plasma, red cell, and liver FC fractions showed a consistent pattern, that of the plasma $C E$ fraction did not. Plasma CE may arise either from hepatic CE or by direct esterification of circulating nonesterified cholesterol (8). Furthermore, the turnover of individual cholesterol esters may vary with the fatty acid to which it is esterified (20). In the experiments reported in this study the relative concentrations of the two isotopic forms of cholesterol were influenced, in addition to these factors, by the relationship between the amount of each isotope free and esterified in the injection mixtures and the degree to which the much more rapid flux of the free cholesterol had been selective. It is not surprising in view of this complex of factors influencing isotopic $\mathrm{CE}$ ratios in these animals that diverse results were obtained.

Several factors indicate, however, that the selective changes in $\mathrm{FC}$ saff/coco observed in the studies of 30 to 90 minutes were not due to isotope originally in the $\mathrm{CE}$ fraction of the injected material: 1) In experiments 1,2, and 3 the saff/ coco of the injected $\mathrm{CE}$ exceeded that of the FC, whereas in 4 and 5 it was lower. Yet in all instances, the same relationship between donor and recipient FC fractions was noted at the end of study. 2) As noted above, at 180 and 210 minutes, re-equilibration of the FC fraction occurred resulting in close agreement between the injected saff/coco and that of whole serum (no. 7) or the $<1.019$ fraction (no. 6) obtained at the end of the experiments. Had CE isotope made a significant contribution to FC saff/coco in these experiments, one would expect variation from this original FC ratio, since in one experiment $\mathrm{CE}$ saff/coco exceeded and in the other was less than that of the FC. 3) The in vitro studies indicate selective dynamics of the lipoprotein FC independent of $\mathrm{CE}$, since in vitro labeling was restricted to the nonesterified cholesterol.

The present study may provide an insight into the mechanism by which the ingestion of unsaturated dietary fat produces an increase in tissue cholesterol content (21-23). In at least one study in which this hypocholesterolemic effect was observed in rats (24), a fall in plasma concentration occurred as tissue content rose. These findings suggest that the hypocholesterolemic effect of unsaturated dietary fat could result from an al- teration in lipoprotein structure such that the equilibrium between plasma and tissue cholesterol pools is altered to favor the latter. Differences in the dynamics of free cholesterol between lipoproteins with different fatty acid composition demonstrated in the present study support this postulation if the observed selective shifts of isotope represent net transfer of cholesterol from the injected to recipient tissues.

The evidence for this proposition is further limited, however, by the extent to which the results of the present and other studies utilizing animals are relevant to the mechanism by which human circulating $\beta$-lipoprotein cholesterol is lowered by unsaturated dietary fat. First, the hypocholesterolemic effect regularly produced in man (25, $26)$ is frequently not seen in animals. In the present study and others previously reported (21, 22) higher plasma cholesterol values were often found in animals receiving unsaturated fat. Secondly, both thoracic duct chylomicra and the lipoproteins characteristic of the induced lipemias in animals usually studied in these experiments are quite different from those of human $\beta$-lipoproteins. In the present study, the very high cholesterol content relative to that of other lipid classes (Table I) is peculiar to the $<1.019$ lipoprotein fraction of rabbits made lipemic by a high fat, cholesterolcontaining diet. It is important to point out, however, that in spite of a wide range of cholesterol/ triglyceride and cholesterol/phospholipid ratios in the injected materials, selective distribution was regularly observed.

\section{Summary}

An experiment devised to test the effect of fatty acid composition on the dynamics of very low density lipoprotein free cholesterol is described. The $<1.019$ lipoprotein fraction of rabbits made lipemic with safflower or coconut oil was labeled with either $4-\mathrm{C}^{14}$ - or $7 \alpha-\mathrm{H}^{3}$-cholesterol. This fraction from a safflower-fed rabbit was mixed with one from a rabbit fed coconut oil; each was labeled with a different isotope and the mixture injected into a recipient animal. The free cholesterol isotope ratio in the whole serum, $<1.019$ and $>1.019$ lipoprotein fractions, red cells, and liver-free cholesterol was compared to that injected. The disappearance of isotopic cholesterol 
from $<1.019$ fractions obtained from safflowerfed donors and its appearance in the recipient's red cells, liver, and $>1.019$ lipoprotein fraction was more rapid than that from coconut-fed donors. Similarly, in in vitro studies, exchange of free cholesterol between lipoproteins and red cells was more rapid for the safflower-fed animals.

\section{Acknowledgments}

The author is indebted to Mrs. G. Rabkin, Mrs. V. Leonard, and Mr. D. Ganz for their excellent technical assistance.

\section{References}

1. Hagerman, J. S., and R. G. Gould. The in vitro interchange of cholesterol between plasma and red cells. Proc. Soc. exp. Biol. (N. Y.) 1951, 78, 329.

2. Lossow, W. J., N. Brot, and I. L. Chaikoff. Distribution of the cholesterol moiety of a chylomicroncontaining lipoprotein fraction of chyle in the rat. J. Lipid Res. 1962, 3, 207.

3. Eckles, N. E., C. B. Taylor, D. J. Campbell, and R. G. Gould. The origin of plasma cholesterol and the rates of equilibration of liver, plasma, and erythrocyte cholesterol. J. Lab. clin. Med. 1955, 46,359

4. Minari, O., and D. B. Zilversmit. Behavior of dog lymph chylomicron lipid constituent during incubation with serum. J. Lipid Res. 1963, 4, 424.

5. Roheim, P. S., D. E. Haft, L. I. Gidez, A. White, and H. A. Eder. Plasma lipoprotein metabolism in perfused rat livers. II. Transfer of free and esterified cholesterol into the plasma. J. clin. Invest. 1963, 42, 1277.

6. Mangold, H. K. Thin layer chromatography of lipids. J. Amer. Oil Chem. Soc. 1961, 38, 708.

7. Havel, R. J., H. A. Eder, and J. H. Bragdon. The distribution and chemical composition of ultracentrifugally separated lipoproteins in human serum. J. clin. Invest. 1953, 32, 428.

8. Glomset, J. A. Further studies of the mechanism of the plasma cholesterol esterification reaction. Biochim. biophys. Acta (Amst.) 1963, 70, 389.

9. Nelson, G. J. Studies on human serum lipoprotein phospholipids and phospholipid fatty acid composition by silicic acid chromatography. J. Lipid Res. 1963, 3, 71.

10. Horning, E. C., E. H. Ahrens, Jr., S. R. Lipsky, F. H. Mattson, J. F. Mead, D. A. Turner, and W. H. Goldwater. Quantitative analysis of fatty acids by gas-liquid chromatography. J. Lipid Res. 1964, 5, 20.

11. Farquhar, J. W., W. Insull, Jr., P. Rosen, W. Stoelfel, and E. H. Ahrens, Jr. The analysis of fatty acid mixtures by gas-liquid chromatography. Nutr. Rev. (suppl.) 1959, 17, 1.

12. Goldrick, B., and J. Hirsch. A technique for quantitative recovery of lipids from chromatoplates. J. Lipid Res. 1963, 4, 482.

13. Amenta, J. S. A rapid chemical method for the quantification of lipids separated by thin-layer chromatography. J. Lipid Res. 1964, 5, 270.

14. Porte, D., Jr., and R. J. Havel. The use of cholesterol-4-C'-1abeled lipoproteins as a tracer for plasma cholesterol in the dog. J. Lipid Res. 1964, $2,357$.

15. Havel, R. J., and D. S. Frederickson. The metabolism of chylomicra. I. The removal of palmitic acid-1-C ${ }^{14}$ labeled chylomicra from dog plasma. J. clin. Invest. 1956, 35, 1025.

16. Nestel, P. J., and R. O. Scow. Metabolism of chylomicrons of differing triglyceride composition. J. Lipid Res. 1964, 5, 46.

17. Nestel, P. J., R. J. Havel, and A. Bezman. Metabolism of constituent lipids of dog chylomicrons. J. clin. Invest. 1963, 42, 1313.

18. Brot, N., W. J. Lossow, and I. L. Chaikoff. In vitro uptake and hydrolysis, by rat tissues, of cholesterol esters of a very low density, chyle lipoprotein fraction. J. Lipid Res. 1964, 5, 63.

19. Naidoo, S. S., W. J. Lossow, and I. L. Chaikoff. Disappearance of the cholesterol moiety of an injected chylomicron-containing fraction of chyle from the circulation of the rat. J. Lipid Res. 1962, 3, 309.

20. Goodman, D. S., and T. Shiratori. In vivo turnover of different cholesterol esters in rat liver and plasma. J. Lipid Res. 1964, 5, 578.

21. Avigan, J., and D. Steinberg. Effects of saturated and unsaturated fat on cholesterol metabolism in the rat. Proc. Soc. exp. Biol. (N. Y.) 1958, 97, 814.

22. Gerson, T., F. B. Shorland, and Y. Adams. The effects of corn oil on the amounts of cholesterol and the excretion of sterol in the rat. Biochem. J. 1961, 81, 584.

23. Friedman, M., and S. O. Byers. Effects of saturated and unsaturated fat feeding on experimental thromboatherosclerosis. Amer. J. Physiol. 1962, 203, 626.

24. Bieberdort, F. A., and J. D. Wilson. Influence of unsaturated fat on cholesterol- $\mathrm{C}^{\mathbf{1 4}}$ metabolism in the isotopic study state in the rabbit (abstract). Clin. Res. 1964, 12, 264.

25. Ahrens, E. H., Jr., D. H. Blankenhorn, and T. T. Tsaltas. Effect on human serum lipids of substituting plant for animal fat in diet. Proc. Soc. exp. Biol. (N. Y.) 1954, 86, 872.

26. Kinsell, L. W., J. Partridge, L. Boling, S. Margen, and G. Michaels. Dietary modification of serum cholesterol and phospholipid levels. J. clin. Endocr. 1952, 12, 909. 